\title{
- QUE SIGNIFICA TER DIREITO? Mobilizações do direito sob uma perspectiva sociológica'
}

重 Liora Israël ${ }^{2}$

\section{Palavras-Chave}

lei / direito / sociologia / pesquisa empírica / consciência de direito.

\section{Resumo}

O presente artigo propõe uma indagação sobre as condições sociais de mobilizações da lei e do direito, por meio da apresentação de trabalhos teóricos e empíricos. Da sociologia do direito de Max Weber às mais recentes análises sociojurídicas americanas, são postas em relevo as possibilidades de pesquisas relativas às percepções e ao exercício de seus direitos pelas pessoas. 


\title{
WHAT MEANS HAVING RIGHTS? Mobilizing law in a sociological perspective
}

\author{
Liora Israël ${ }^{3}$
}

\section{Keywords}

law / rights / sociology / empirical research / legal consciousness.

\begin{abstract}
This article proposes to question social conditions in which law and rights are mobilized throughout theoretical and empirical works. From Marx Weber's law sociology to the most recent American socio-legal analysis, the focus is on the study opportunities concerning individuals' perception and activation of their rights.
\end{abstract}


Entre o direito dos juristas e o direito que pensamos ter, entre o direito dos livros e os direitos que reivindicamos, esconde-se uma indagação sociológica que, parece-me, é central em relação ao lugar do direito no Estado. De fato, "ter o direito" designa tanto aquilo que pensamos legitimamente merecer, poder fazer, como aquilo que é garantido e permitido pelo direito, no sentido de fundamento jurídico. A lacuna possível entre os dois conceitos é o que abre espaço a uma reivindicação para o direito ou pelo direito: de fato, se não há coincidência entre o que pensamos ter o direito de fazer e aquilo que o direito nos permite fazer, trêstipos de ação são possíveis: a renúncia, a transgressão do direito ou uma ação visando a fazê-lo mudar, seja, por exemplo, por meio de uma ação judicial ou de uma mobilização visando a alterar a lei. É neste espaço em que o direito pode ser mobilizado que me parece interessante refletir, rompendo com as formas de oposição às vezes demasiado fáceis entre o direito de um lado e a sociedade de outro, em termos de disciplinas, de saberes e de concepções políticas, para promover, ao contrário, uma abordagem das ciências sociais atenta ao lugar do direito, inclusive nas formas de mobilização política (Israël, 2009a).

Essa lacuna, que vamos nos empenhar em explorar e que remete à polissemia da palavra direito, encontra-se também entre o singular: "do" direito versus o plural: "dos" direitos. Em inglês, as coisas são ao mesmo tempo mais simples e igualmente complicadas: se por um lado há uma distinção entre direito (law) e direitos (rights), o termo "law" abrange tanto aquilo que designamos pelos termos "lei" e "direito" ... A ambiguidade das terminologias não pode ser verdadeiramente resolvida. Ao contrário, ela remete a um espaço de indeterminação, presente na vida social, que abre justamente a possibilidade de mobilizações entre as reivindicações das pessoas ou dos coletivos e o direito, na medida em que ele cristaliza, realiza (em maior ou menor grau) e simboliza um conjunto de potencialidades (mas também de deveres, de restrições, etc.). A justiça deve ser justa e o direito deve ser direito: se a etimologia justifica essa polissemia, ela também é portadora de sentidos nas nossas sociedades, nas quais o direito e a justiça são dotados de uma forte legitimidade (Corten, 2002), merecendo, portanto, ser levados a sério na análise.

\section{Questões de definição e definição de questões: retorno a Weber, entre direito e direitos}

Essa oposição entre dois sentidos da palavra direito, o direito e o direito a, que podemos também abordar pela tensão entre o direito e os direitos, foi primeiramente pensada pelos próprios juristas, que propuseram analiticamente uma diferenciação entre o que qualificaram de direito dito objetivo versus direitos ditos subjetivos. Para simplificar, o direito objetivo é, nessa perspectiva, considerado como o conjunto das regras jurídicas aplicáveis num país e num momento determinado, num certo contexto político. Por outro lado, os direitos subjetivos compreendem as prerrogativas individuais que são reconhecidas aos indivíduos ou que os indivíduos reconhecem... no direito objetivo. Vinculados às pessoas, esses direitos - quer se trate do direito de propriedade ou dos direitos humanos - podem, por definição, ser reivindicados. Fonte de debates entre os próprios juristas, essa oposição clássica, mas parcialmente problemática (o que dizer, por exemplo, dos direitos subjetivamente per- 
cebidos, mas ausentes do direito objetivo?) deu origem a análises sociológicas, principalmente na obra de Max Weber. O sociólogo alemão, jurista de formação, desenvolveu uma reflexão importante sobre os direitos subjetivos, a qual é, sem dúvida, útil retomar nesta apresentação. Conforme mostra Catherine Colliot-Thélène num artigo sobre "os modos de justificação dos direitos subjetivos" (Colliot-Thélène, 2006), Weber convidanos a considerar que qualquer pessoa goza de um direito em virtude da ordem jurídica em vigor numa sociedade determinada, quando tem uma "oportunidade" garantida pelo sentido de uma norma jurídica, de obter o apoio de um "aparelho de constrangimento" coletivo em favor de interesses precisos, quaisquer que sejam, particularmente, sua natureza, matérias ou concepções. Os direitos subjetivos no sentido weberiano são, portanto, garantidos pelo direito dito objetivo ou "positivo", mas podem também ser exercidos porque há instituições capazes de garanti-los, inclusive pela força (monopólio do Estado na sua forma legítima). A isso deve ser acrescentado - terceiro elemento - que esses direitos subjetivos estão associados a interesses de diferente tipo. O mundo no qual esse direito é exercido é, portanto, povoado por atores dotados de interesses, que atuam num ambiente no qual intervêm as instituições dotadas de poder. Weber distingue, então, três tipos de prescrições jurídicas, diz Catherine Colliot-Thélène: elas podem ser imperativas, proibitivas ou permissivas. Nesta circunstância, é este terceiro tipo que nos interessa aqui, na medida em que "todo direito subjetivo é uma fonte de poder que, por causa da existência da prescrição jurídica em questão, pode sobrevir no caso específico àquele que, sem tal prescrição, estaria totalmente indefeso" (Max Weber, citado em Colliot-Thélène, 2006, p. 92). O que é particu- larmente interessante nessa tese é a ideia segundo a qual um direito subjetivo fundado no direito positivo é uma fonte de poder para aquele que, de outra forma, estaria desamparado. Weber já apontara que esse terceiro tipo, que corresponde aos "direitos" no plural, estava em plena ascensão. Com efeito, as sociedades de mercado caracterizam-se pela existência de liberdades formalmente reconhecidas que correspondem ao fato de se ter direitos, enquanto as sociedades sem mercado são associadas no modelo weberiano às prescrições imperativas e proibitivas.

Entre essas prescrições permissivas, Weber distingue ainda mais precisamente, de acordo com Catherine Colliot-Thélène, entre os Freiheitsrechte, que podemos traduzir por "direitos-liberdades", que protegem contra os entraves exercidos por um terceiro e especialmente pelo Estado - por exemplo, a liberdade de circulação - e uma segunda categoria, que ele não nomeia especificamente e que corresponderia às prescrições que concedem aos indivíduos a liberdade de regular dentro de certos limites as suas relações mútuas (como o direito de contratar). Na sua sociologia da dominação, Weber insistiria mesmo no fato de que esses direitos-liberdades são mesmo por definição os direitos humanos, que garantem uma liberdade do indivíduo em relação ao poder e, em particular, ao Estado. Catherine Colliot-Thélène avança em tais reflexões em direção a uma análise das relações entre desenvolvimento do Estado, desenvolvimento dos mercados e direito. Mas do ponto de vista da reflexão desenvolvida aqui, a sua análise dos direitos subjetivos em Weber é particularmente preciosa na medida em que ela faz da sua história a história da modificação da compreensão do fundamento dos direitos que um indivíduo 
pode reclamar, em virtude de uma garantia que é sempre o fato de uma coletividade.

Outra dimensão importante dessa reinterpretação de Weber remete para a pertinência da perspectiva socio-histórica. Quando trabalhamos sobre os direitos, é importante de fato refletir sobre a sua gênese e sobre as condições que os tornam concebíveis - ou não - em uma sociedade. Além disso, deve-se salientar, como faz Colliot-Thélène, o fato que os direitos que se podem reivindicar também são sempre poderes, e que remetem a coletividades que os garantem, permite conduzir a uma análise empírica desses direitos orientada tanto para a sua ativação como para o destaque das coletividades sobre as quais eles se apoiam. O fato de refletir sobre a construção das coletividades na compreensão da elaboração de novos direitos convida a uma orientação sociológica sensível aos efeitos mútuos ou constitutivos, para citar Alan Hunt (1993), dos direitos e daqueles que os reivindicam. Isso não significa necessariamente que aqueles em nome dos quais estão sendo reivindicados tomam-nos para si mesmos, como bem demonstrou Kristin Bumiller em relação às vítimas de discriminação (Bumiller, 1988).

Ao comentar, por sua vez, a sociologia do direto de Max Weber, Romain Melot (2006) enfatiza a dimensão das antecipações ligadas aos direitos subjetivos: "As pretensões [no sentido de pretender algo] que os atores têm em função do seu direito são um tipo de interpretação que define sociologicamente a natureza dos 'direitos subjetivos' como regras de direitos que criam expectativas e pretensões legítimas por parte dos indivíduos "(p.112). Essa articulação entre direito e direitos, que enfatiza a capacidade dos atores de se apropriarem do direito, vai efetivamente na direção de uma análise so- ciológica dos modos de ativação do direito para fazer valer os direitos. Nessa perspectiva, pretender algo e acreditar que isto é legítimo são duas faces indissociáveis de uma compreensão dos "seus" direitos ou do seu legítimo direito, mesmo que ainda seja preciso saber como as pessoas avaliam qual é o seu direito, como o reivindicam e que fundamentos dão a essa reivindicação. Melot também integra na análise, graças a um conhecimento detalhado dos diversos textos de sociologia do direito de Weber, o papel que as instituições desempenham - particularmente sob a influência de Jehring - nesse quadro. Elas constituem, para os atores, os lugares onde são confrontados os fundamentos que eles dão à orientação dos seus comportamentos pelo direito. Nesse contexto, continua Melot, a instituição jurídica é "tudo, menos o panóptico de Bentham. Ela surge mais como uma moldura para o desenvolvimento dos direitos em que a tomada em consideração de uma autoridade estatal de garantia é integrada pelos cálculos dos indivíduos" (p.125).

Articular um direito à percepção pelos atores dos seus direitos supõe, assim, traçar inter-relações e circulações de reivindicações, de sentidos e de conhecimentos entre pessoas, coletividades, instituições. Uma perspectiva sociológica é, portanto, plenamente justificada e abre ricas problemáticas de investigação. Como as pessoas conscientizam-se dos direitos "subjetivos" e depois os relacionam com a existência ou não de direitos objetivos, passíveis, por exemplo, de serem oponíveis a outras partes num processo? Ao contrário do que pode sugerir a literatura jurídica, não há nada menos óbvio do que a transformação de um litígio privado em litígio judicial, pelo menos para a grande maioria das pessoas que não têm 
formação jurídica nem o hábito de recorrer a um advogado. É necessário, portanto, destacar as operações concretas que permitem ou não vincular as expectativas e as reivindicações, as reclamações e a sua formatação legal. Um segundo conjunto de questões, uma vez identificados os direitos existentes, consiste em interrogar-se sobre as condições eventuais das reivindicações em termos da aplicação de direitos existentes ou da criação de direitos. Similarmente, também é importante interessar-se pelo modo como as instituições atuam, em particular as judiciais, e dentro delas os atores que têm por objeto justamente divulgar ou promover os direitos para as pessoas. Quais são os usos do direito que eles levam, estimulam e desenvolvem nessa perspectiva, ou, ao contrário, quais são os obstáculos que podem existir para a difusão de direitos? Para dar um exemplo, é provável que um agente administrativo não chegue ao ponto de incitar que se ajuíze uma ação contra a sua própria administração.

\section{Perspectivas de pesquisa}

As questões abordadas até agora podem parecer abstratas, mas são necessárias para aclarar o interesse de uma sociologia do direito que tenta levar o direito e as suas categorias a sério, enquanto faz parte de uma corrente de pensamento que não é a dos juristas, pelo menos franceses, e seja apoiada por pesquisas empíricas. Para dar diversos exemplos, nos diferentes níveis mencionados, e que se referem, de cada vez, a trabaIhos muito diferentes das ciências sociais, três linhas de pesquisa podem ser traçadas, ilustradas por trabalhos recentes.

Um primeiro exemplo contemporâneo, bastante visível, diz respeito às mobilizações do "sem-". Particularmente, como é que os sem - papeis, sem-emprego ou sem-teto conseguem integrar a dimensão jurídica nas suas mobilizações? Esse é o cerne do problema que essas mobilizações possuem no cenário público, caracterizado tanto pelo quadro jurídico desfavorável que essas populações enfrentam, como pela dificuldade de acesso que o seu tecnicismo representa para elas. No entanto, essas mobilizações, desde a década de 1990 especialmente, têm se baseado amplamente na referência ao direito, associando-o ao nome das suas organizações (Droit au Logement ${ }^{4}$, Droits devant!! ${ }^{5}$, etc.). Como Daniel Mouchard (2003) mostrou bem, o direito é para esses movimentos um "recurso ambivalente", que dá uma legitimidade à sua luta, ao mesmo tempo que os coloca numa situação de dependência em relação ao Estado e ao reconhecimento que ele pode ou não Ihes dar. De fato, uma das saídas para essas contestações ao direito existente é a mudança do direito, que depende do legislador.

Um segundo tipo de pesquisa distingue-se da análise das mobilizações para se voltar, ao contrário, para uma sociologia das práticas quotidianas. É de fato relevante investigar como as pessoas, no seu confronto com as burocracias das repartições públicas, reivindicam ou negociam o acesso aos seus direitos, especialmente aos seus direitos sociais, na prefeitura, na previdência social, etc. Yasmine Siblot (2006), no livro publicado a partir da sua tese, propõe uma etnografia detalhada dessas relações no nível mais local, em que há o intercâmbio e são construídas

NT: associação francesa de defesa dos interesses dos sem-teto $e$ das pessoas em condições precárias de moradia, cujo nome significa Direito à Habitação.

${ }^{5}$ NT: associação francesa que tem por objeto no seu estatuto "a luta por todos os direitos" e cujo nome significa Direitos Antes. 
relações entre usuários e agentes públicos ${ }^{6}$, entre titulares e provedores (ou não) de direitos, que se traduzem por ajudas tangíveis ou intangíveis, por reconhecimentos mútuos (ou não), por elos interpessoais que estabilizam, perturbam, encarnam essas relações. Neste contexto, o direito assume mais a forma de modos condução de processos, e os direitos são concretizados na "papelada" que deve ser adequadamente preenchida e produzida, para utilizar os termos das pesquisas de Yasmine Siblot.

Terceira orientação de pesquisa: também é possível, apoiando-se em bases totalmente diferentes, articular o direito aos direitos ao questionar o que cobrem exatamente os direitos chamados "da defesa", frase feita que tende a entravar a diversidade das relações entre um advogado e seu cliente, por detrás do biombo da ação do defensor no tribunal. No entanto, especialmente quando se trata de processo com dimensão política, em que os réus têm, frequentemente, uma opinião sobre as implicações políticas e jurídicas do processo, a escolha da estratégia judicial e os usos estratégicos dos direitos da defesa para se fazer compreender no processo suscitam diversas questões. Como pude demonstrar ao ocupar-me das mobilizações políticas características dos anos 1970 (Israel, 2009b), os ativistas e as suas organizações têm sido, num certo número de casos, com seus advogados, os atores estrategistas da sua própria defesa e da sua visibilidade, ajudando a politizar os limites e a produção de um direito supostamente neutro.

Essas três áreas de pesquisa, relativamente díspares, permitem destacar, sem esgotar, a diversidade possível de temas e de ângulos de observação, e a maneira como eles situ-

am-se mais ou menos distantes das abordagens dos próprios juristas. Mesmo antes de surgir a questão da pesquisa empírica e das suas modalidades práticas, é na concepção de uma sociologia do direito "em ação" que se situa a ruptura epistemológica com as pesquisas jurídicas. Em vez de assumir uma obviedade do direito (e do não-direito), e uma automaticidade corolário do recurso à justiça em caso de litígio como fazem os juristas, a abordagem sociológica permite reconhecer a dificuldade dos atores para identificar quais são os seus direitos e como efetivá-los, e a maneira pela qual o horizonte judiciário está frequentemente distante, problemático, inacessível ou mesmo assustador para eles. Enquanto o objeto das análises jurídicas é muitas vezes o direito nas suas formas elaboradas, pois, por exemplo, a jurisprudência estudada corresponde, na melhor das hipóteses, ao nível dos acórdãos dos tribunais de segunda instância e, mais frequentemente, dos acórdãos dos tribunais superiores, a sociologia do direito também está preocupada com todas as pequenas decisões e não-decisões proferidas, não apenas nas jurisdições inferiores (de primeira instância, autoridades de polícia...), mas também nos guichês administrativos que aplicam diariamente as diversas leis (da lei da seguridade social à da nacionalidade, passando pela lei tributária (Delalande \& Spire, 2010)).

Se as pesquisas como as que acabaram de ser mencionadas puderam ser conduzidas, isto não está necessariamente dentro da estrutura explícita da sociologia do direito (por exemplo, no que diz respeito a Yasmine Siblot), nem numa perspectiva global que permitiria articular os elementos que gradualmente permitem trazer à luz o espaço dessas utilizações do direito para fazer valer 
os direitos. Para construir este quadro, além da clara adoção de um ponto de vista empírico sobre o direito, com base nas concretizações da renovação da sociologia do direito na França desde meados da década de 1980 - ilustrada em particular pelo reaparecimento da revista Droit et Société a partir de 1986 - pode ser útil referir-se a outras tradições de pesquisa pré-existentes, e em particular aos trabalhos que puderam ser conduzidos nos Estados Unidos, inicialmente na corrente de pesquisa "Law and Society". Se não é possível voltar aqui para a história dessa corrente (Vauchez, 2001), é necessário apresentar as pesquisas pioneiras que vêm desta tradição herdeira da corrente realista de análise do direito, em particular no que diz respeito às condições de sua mobilização. Essa referência a trabalhos norte-americanos implica evidentemente um perigo: o de estabelecer a análise sobre uma situação diferente, particularmente do ponto de vista da sua cultura jurídica. No entanto, sob a condição de pensar na comparação de maneira rigorosa, a questão do direito não me parece ser substancialmente diferente, a esse respeito, dos imperativos que regem os outros domínios da vida social.

\section{Perspectivas norte-americanas}

O texto que constitui a principal referência sobre a questão, ao qual foi brevemente feita referência acima, é frequentemente resumido pela trilogia "naming, blaming, claiming". Traduzido para o francês na revista Politix sob o título: L'émergence et la transformation des litiges : réaliser, reprocher, réclamer (Abel, Felstiner, Sarat, 1991) - "O surgimento e a transformação de litígios: realizar, culpar, reivindicar", este artigo é essencial para compreender, como já dissemos, tan- to todas as etapas de uma reivindicação de direitos através do processo judicial como todos os obstáculos que podem opor-se a ela. Da mesma forma, também nos convida a ter em mente que o contencioso existente, isto é, os litígios ajuizados nos tribunais para manifestar diferentes tipos de reivindicações, constituem apenas a ponta do iceberg, uma fração ínfima das expectativas e dos sentimentos de injustiça que os cidadãos podem ter. Isso permite mostrar que levar em consideração os litígios apenas ao nível dos tribunais, visível na associação frequente a nível estatístico entre conflito social e recurso à justiça, oblitera os passos indispensáveis que são a conscientização do dano sofrido e a atribuição de responsabilidade a terceiros, antes mesmo de se considerar o acesso ao judiciário. Assim, contra a concepção muito difundida de uma sociedade norte-americana que é muito contenciosa, à qual cada vez mais assemelhar-se-ia uma sociedade francesa às vezes caracterizada por sua "judicialização", responde inversamente à constatação de uma acessibilidade muito limitada às instâncias judiciais, em particular para os mais desfavorecidos, e no caso de trabalhos norte-americanos a uma chamada para uma reversão dessa concepção, para promover a utilização dos tribunais pelo maior número de pessoas. Este apelo lançado em conclusão por Abel, Felstiner e Sarat é, aliás, retomado mais de vinte anos depois por um dos seus principais herdeiros, Michael McCann. A obra que ele escreveu com William Haltom (Haltom \& McCann, 2004) destaca como a tese de um recurso excessivo aos tribunais - e particularmente o enfoque em algumas "histórias" amplamente divulgadas pela mídia, como aquela que trata do valor da indenização concedida a uma mulher queimada por café comprado numa famosa cadeia de 
fast food - foi algo em que os meios patronais carregaram nas tintas, ávidos por reduzir os direitos dos consumidores. Os autores sublinham como o crescimento do recurso aos tribunais tantas vezes invocado, por exemplo, em termos de erro médico, nunca foi demonstrado, enquanto serve como um discurso de justificação, por exemplo, para se aumentarem as tarifas de seguros saúde. Assim, tudo acontece como se a ameaça de recurso ao direito estivesse mais presente, com um conjunto de efeitos reais, sem que a realidade de uma utilização mais acessível dos tribunais fosse comprovada. Elementos similares foram destacados na França, por exemplo, no que diz respeito ao recurso aos tribunais de trabalho, que, ao contrário do que muitos relatórios mencionam, está em queda, como mostram Brigitte Munoz Perez e Evelyne Serverin (2005). Portanto, não é tanto o recurso aos tribunais que aumentaria e explicaria o aumento real do número de processos, mas a crescente penalização de um certo número de condutas que aumentam mecanicamente a atividade dos tribunais (por exemplo, de tribunais administrativos em matéria de imigração).

As linhas de pesquisa mais relevantes pressupõem, assim, que se libertem das representações habituais referentes à justiça ("muito lenta", "cada vez mais solicitada", "inacessível"...) para se focar nas utilizações mais concretas do direito e na tomada de consciência dos seus direitos pelos atores que os tornam possíveis ou não. É desse modo que Laura Beth Nielsen (2008) apresenta o problema num inspirado artigo de síntese visando a compreender como os direitos funcionam ao nível dos indivíduos e possibilitam um certo número de condutas. $O$ artigo parte da ideia segundo a qual a ligação entre justiça social e direitos legais está no centro da pesquisa de várias disciplinas: um direito não é redutível ao seu objeto único (a propriedade, a habitação, etc.), mas é uma reivindicação que tem a ver com a justiça, a legitimidade, o poder ou a resistência ao poder. Laura Beth Nielsen levanta questões interessantes que são abordadas apenas recentemente na sociologia francesa, como a análise dos processos pelos quais cidadãos comuns referem-se aos direitos, invocam-nos ou não os invocam. Quais são os efeitos práticos de um direito quando ele é reivindicado? Por que razão alguns atores o reivindicam e outros não ${ }^{7}$ ? Por que razão apenas algumas dessas reivindicações são bem-sucedidas? O artigo fornece respostas para questões aparentemente simples, mas que questionam a cadeia de produção do direito: quem mobiliza direitos, em que contextos e com que efeitos?

Em geral, a teoria política distingue entre três gerações de direitos, numa perspectiva igualmente relevante para a nossa problemática, uma vez que permite distinguir até que ponto esses diferentes direitos podem constituir-se recursos, e em que limites, para os cidadãos. A primeira geração de direitos refere-se à liberdade e à autonomia: estão associados aos fundamentos das democracias liberais, como a liberdade de opinião, a liberdade de expressão... Estes são principalmente direitos "negativos", no sentido em que visam a proteger o indivíduo, especialmente do Estado - sendo essa tradição particularmente significativa nos Estados Unidos - mesmo que contenham disposições "positivas", como o direito à participação política ou ao tratamento justo. A segunda geração de direitos diz respeito sobretudo às dimensões sociais, econômicas,

A questão do não-acesso aos direitos sociais foi analisada de forma pioneira na década de 1990 por Philippe Warin e sua equipe em Grenoble, que hoje lideram um observatório do não-acesso aos direitos e serviços: http://odenore.msh-alpes.fr/ 
ao bem-estar. Pode-se incluir aí o direito ao trabalho, à habitação, à educação, tipos de direitos que estão presentes, no caso francês, no Preâmbulo da Constituição de 1946. Esses direitos, assim como aqueles ditos da primeira geração, são individuais, mas distinguem-se dos direitos ditos formais pela sua dimensão substancial. A sua elaboração remete ao fato de que o exercício dos direitos civis e políticos permanece praticamente virtual na ausência de condições socioeconômicas mínimas. Finalmente, o que é referido como a terceira geração de direitos diz mais respeito a dimensões coletivas, como o direito a um ambiente saudável, à paz, mas também à preservação de costumes ou de tradições. A promulgação desses direitos geralmente confere uma responsabilidade ao Estado, que se vê encarregado de proteger alguns desses direitos coletivos. No caso norte-americano, os povos indígenas nativos minoritários podem, portanto, avocar a fruição de direitos que não Ihes puderam ser garantidos pelas duas primeiras ondas. Além disso, esses direitos têm a particularidade de contribuir para a estabilização das coletividades cujos membros veem reconhecidos direitos específicos. Assim, eles propõem a sua definição por relações de inclusão ou exclusão (americano nativo/americano não-nativo, homem/mulher, branco/negro, etc.) que tendem a sobreporse aos contornos formais da cidadania.

Essa cronologia é frequentemente apresentada como uma progressão para uma concepção dos direitos cada vez mais inclusiva, assegurando não só a proteção dos indivíduos e depois dos grupos, mas também o seu reconhecimento, valor cuja importância foi particularmente enfatizada pelo filósofo e sociólogo alemão Axel Honneth (2000). No entanto, no que diz respeito a esta cronologia, que parece ir no sentido de uma realização e de um triunfo de uma retórica de direitos cada vez mais extensa, desenvolveram-se críticas dos direitos. Uma crítica política foi feita por aqueles que pensavam que essa extensão infinita marcava um aumento ilimitado no papel do Estado ou, pelo contrário, retirava sentido à noção de direito(s). Uma crítica mais acadêmica também emergiu, nos anos seguintes à aparente vitória consagrada pelas principais decisões da Suprema Corte dos EUA, particularmente em relação aos direitos civis (Brown vs Board of Education) e depois ao aborto (Roe vs Wade). Ao mesmo tempo que constituem pontos de referência essenciais, essas importantes decisões legitimaram uma linguagem de direitos que fornece fundamentos de ação dos quais os demandantes se poderiam valer e que foram reconhecidos pelos tribunais, no aparente sentido de um progresso social, de mais justiça. No entanto, ao mesmo tempo, essas decisões podem ter levado a crer que os problemas estavam resolvidos, que a justiça "estava indo na direção certa", em oposição às dificuldades práticas destacadas pelas obras já citadas sobre a dificuldade de acesso ao direito, ou ainda fazendo esquecer o quanto os direitos são socialmente construídos, ou mesmo orientados ideologicamente (o que tem sido particularmente o objeto da crítica feminista ao direito). A crítica dos direitos tomará muitas facetas no trabalho das ciências sociais, desde a denúncia do "mito dos direitos", que leva, contudo, em conta a sua eficácia social, como em Stuart Scheingold (2004), até os críticos mais radicais que veem uma armadilha, as vitórias mais visíveis resultando em respostas políticas violentas e um desengajamento militante, sem garantir que elas realmente serão im- 
plementadas na prática (Rosenberg, 2008). Para Gérald Rosenberg, a luta por meio do direito pelos direitos é assim uma isca, mais cara e muito menos efetiva do que a luta direta no campo político. Ao mesmo tempo, uma corrente mais teórica, os "critical legal studies", na interseção do direito e da filosofia, levará a uma desconstrução radical dessa retórica de direitos considerada falaciosa. Mais moderadamente, trabalhos empíricos retomaram esse debate e mostraram que era necessário medir os efeitos do recurso à justiça não apenas em termos de vitória/derrota judicial, mas também integrando a tomada de consciência dos seus direitos por parte das pessoas mobilizadas, por exemplo, as mulheres que lutaram contra a desigualdade salarial (McCann, 1994). Essa linha de pesquisa, que vem crescendo desde os anos 1990, ajudou a ampliar o estudo sociológico dos direitos da análise apenas das instituições jurídicas e judiciais, e levou em conta o nível dos atores no seu comportamento social mais cotidiano. Este é particularmente o caso de Laura Beth Nielsen, que num artigo e depois num livro, interessouse pela questão da tolerância às condutas agressivas de interpelação em áreas urbanas, em relação à primazia concedida à liberdade de expressão nos EUA (Nielsen, 2004). Inscritos na esteira de pesquisas sobre a consciência do direito (Pélisse, 2005), essas pesquisas pioneiras, contudo não resolveram completamente a questão da articulação entre direito e direitos, especialmente porque o deslocamento da análise para a apreensão do direito na vida cotidiana e as formas comuns de se referir aos direitos podem, por sua vez, ter levado a enfraquecer o lugar das instituições e, em particular, o papel dos intermediários profissionais, como os advogados.

\section{Conclusão}

A época contemporânea pode ser caracterizada pela força simbólica de uma expressão em termos de direitos, sejam os direitos da criança, dos animais, mas também do meio ambiente (do qual pode medir-se hoje em dia os prejuízos sofridos e ter o seu reconhecimento jurídico, cf. Fourcade, 2011). Além do fato de que essa extensão da linguagem dos direitos carrega consigo uma dimensão de personalização cujas consequências nem sempre são medidas (Hermitte, 2011), essa expansão quase ilimitada, geralmente considerada como um progresso ao nível do direito, permanece mal conhecida do ponto de vista dos seus efeitos sociais. Em particular, é possível que nessa área, como em outras, uma extensão das áreas cobertas pela direito, possa ter paradoxalmente aumentado a vulnerabilidade em relação ao Estado e a dependência relativamente aos operadores especializados do direito que são os juristas, como pude mostrar em relação ao direito dos estrangeiros (Israël, 2003), como também aparece em relação à lei DALO (lei francesa que institui o direito à habitação droit au logement opposable - "Loi DALO"). Além disso, as obras bem-vindas, mas ainda raras, que focam a atenção na expressão de novas reivindicações em termos de direitos ou na busca de reconhecimento passando pelo direito (para minorias, descendentes de vítimas, etc.) negligenciam muitas vezes, como resultado, aqueles que apelam aos direitos a partir de uma posição que é menos de reivindicação e que remente muito mais à condição de súplica, de demanda de proteção. Um conjunto de trabalhos muito recentes, influenciados pelas pesquisas sobre a consciência do direito (Ewick \& Silbey, 1998), voltou-se para essas questões, a fim de descobrir por que motivo e como as 
pessoas na França dirigem-se às novas instituições encarregadas de defender os seus direitos, e entre elas significativamente o "Défenseur des droits", ou como os prisioneiros pleiteiam o respeito aos seus direitos ${ }^{9}$ pelo Defensor das liberdades. Esses trabaIhos constituem uma frente avançada das pesquisas atuais sobre o Estado de direitos, para usar o título de um recente simpósio'o, que visa a entender melhor o que a crescente referência aos direitos está fazendo nas nossas sociedades, seja do ponto de vista da facilitação ou do obscurecimento do recurso ao direito e às suas instituições tradicionais, do surgimento de novas referências e de modos de ação alternativos - em especial diante de agências dedicadas ou por incorporação de novos imperativos por organizações privadas (Bereni, 2009), e finalmente relativamente ao tipo de definição de cidadania que se constitui. A multiplicação de direitos invocáveis pode, de fato, ser considerada como uma fonte eternamente renovada de reivindicações e de mobilizações, do direito à soberania alimentar" à promulgação de textos normativos propondo considerar o acesso à Internet como um direito fundamental. Mas essa acumulação também leva a alguma confusão, relacionada tanto às instâncias relevantes para aplicar essas normas como à realidade da sua disseminação. A expansão ilimitada da referência aos direitos poderia muito bem contribuir para enfraquecer um direito tornado

\footnotetext{
3 Hoje, o Défenseur des droits (Defensor dos direitos) reúne as instituições recentes responsáveis pelo combate à discriminação na sequência da Halde - Alta Autoridade Francesa de Luta contra a Discriminação e pela Igualdade (Chappe, 2011), pela resolução de litígios com as administrações públicas (Baudot \& Revilard, 2011) ou pela defesa das crianças.

${ }^{9} \mathrm{Cf}$. a tese de mestrado em curso de Corentin Durand (Sociologia, EHESS).

${ }^{10}$ Simpósio "O Estado dos Direitos. Práticas de Direitos na Ação Pública ( LL'État des droits. Pratiques des droits dans l'action publique ») organizado por A. Revillard e P.-Y. Baudot, CERAL - Université Paris 13 Villetaneuse-CEE Sciences Po Paris, 25 e 26 de junho de 2012
}

"Ver a tese em curso de Delphine Thivet, e especialmente Thivet, 2012 cada vez menos visível pela superposição de ordens normativas, e obscurecer pelo reconhecimento assim distribuído os efeitos incertos da sua frágil implementação.

\section{Referências}

Abel, R. L., Felstiner, W. L. F. \& Sarat, A. (1991). L'émergence et la transformation des litiges : réaliser, reprocher, réclamer... Politix, 16 (4), 41-54.

Baudot, P.-Y., \& Revillard, A. (2011). Le Médiateur de la République : une instrumentation de la démocratie administrative. Revue Française d'Administration Publique, 137-138(1), 193-207.

Bereni, L. (2009). "Faire de la diversité une richesse pour l'entreprise". La transformation d'une contrainte juridique en catégorie managériale. Raisons politiques, 35, pp. 87-106

Bumiller, K. (1988). The Civil Rights Society: The Social Construction of Victims. Baltimore: The John Hopkins University Press. France.

Chappe, V.-A. (2011). Le cadrage juridique, une ressource politique? La création de la Halde comme solution au problème de l'effectivité des normes antidiscrimination (1998-2005). Politix, 94, 107-130.

Colliot-Thélène, C. (2006). Les modes de justification des droits subjectifs. In J.-Ph. Heurtin \& N. Molfessis (dir.). La sociologie du droit de Max Weber (pp. 89106). Paris : Dalloz

Corten, O. (2002). La persistance de l'argument légaliste : éléments pour une typologie contemporaine des registres de légitimité dans une société libérale. Droit et Société, 50, 185-203.

Delalande, N., \& Spire, A. (2010). Histoire sociale de l'impôt. Paris : La Découverte.

Ewick, P., \& Silbey, S (1998). The Common Place of Law: Stories from Everyday Life. Chicago: Chicago University Press.

Fourcade, M. (2011). Cents and Sensibility: Economic Valuation and the nature of "nature". American Journal of Sociology, vol. 116, 6, 1721-1777.

Haltom, W., \& McCann, M. (2004). Distorting the Law: Politics, Media, and the Litigation Crisis. Chicago: The University of Chicago Press.

Hermitte, M.-A. (2011). La nature, sujet de droit ? Anna- 
les. Histoire, sciences sociales, vol. 66, 173-212.

Honneth, Axel (2000). La lutte pour la reconnaissance. Paris : Cerf

Hunt, Alan (1993). Explorations in Law and Society: Toward a Constitutive Theory of Law, New York: Routledge.

Israël, L. (2003). Faire émerger le droit des étrangers en le contestant, ou l'histoire paradoxale des premières années du GISTI. Politix, vol. 16, 62, 115-143.

Israël, L. (2009a). L'arme du droit. Paris: Presses de Sciences Po.

Israël, L. (2009b). Un droit de gauche. Rénovation des pratiques professionnelles et nouvelles formes de militantisme des juristes engagés dans les années 1970. Sociétés contemporaines, 73, 41-71.

McCann, M. (1994). Rights at Work, Pay Equity Reform and the Politics of Legal Mobilization. Chicago: The University of Chicago Press.

Melot, R. (2006). Les droits subjectifs, de la rationalisation des sociétés à la théorie de l'action. In J.-Ph. Heurtin \& N. Molfessis (dir.). La sociologie du droit de Max Weber (pp. 77-82). Paris : Dalloz.

Mouchard, D. (2003). Une ressource ambivalente: les usages du répertoire juridique par les mouvements des « sans ». Mouvements, 29, 55-59.

Munoz-Perez, B., \& Serverin, E. (2005). Le droit du travail en perspective contentieuse. Paris : Ministère de la justice.

Nielsen, L. B. (2004). Licence to Harass. Law, Hierarchy and Offensive Public Speech. Princeton: Princeton University Press.

Nielsen, L B. (2008). The Work of Rights and the Work Rights Do: a Critical empirical Approach. In A. Sarat (dir.). The Blackwell Companion to Law and Society. Oxford: Blackwell Publishing.

Pélisse, J. (2005). A-t-on conscience du droit ? Autour des Legal Consciousness Studies. Genèses, 59, 114-130. Rosenberg, G. (2008[1991]). The Hollow Hope. Can Courts Bring About Social Change. Chicago: The University of Chicago Press.

Scheingold, S. (2004 [1974]). The Politics of Rights. Laywers, Public Policy and Political Change. Ann Harbor: University of Michigan Press.

Siblot, Y. (2006). Faire valoir ses droits au quotidien, les services publics dans les quartiers populaires. Paris: Les Presses de Sciences Po.

Thivet, D. (2012). Des paysans contre la faim. La « souveraineté alimentaire ", naissance d'une cause paysanne transnationale. Terrains \& Travaux, 20, 69-85.
Vauchez, A. (2001). Entre droit et sciences sociales: retour sur l'histoire du mouvement Law and Society. Genèses, 45, 134-149. 